\title{
O "desafio da modernidade" e as artes marciais chinesas: uma análise sobre a inclusão do Wushu nos Jogos Olímpicos
}

http://dx.doi.org/10.11606/1807-5509201800020207

\author{
Marcio Antonio TRALCI FILHO,,***
}

* Escola de Educação

Física e Esporte,

Universidade de São

Paulo, São Paulo, SP,

Brasil.

** Instituto de

Psicologia,

Universidade de São

Paulo, São Paulo, SP

Brasil.

\section{Resumo}

As artes marciais chinesas (Kung Fu ou Wushu) provavelmente são uma das práticas culturais mais populares que cruzaram as fronteiras da China. De acordo com a Federação Internacional de Wushu existem federações nacionais de Wushu na maioria dos paises de todos os continentes, configurando 146 federações membros. Além disso, o IWUF é a entidade responsável por pleitear o Wushu como esporte olímpico. Diante disso, o objetivo do artigo é analisar a relação dinâmica entre tradição e modernidade em alguns dos argumentos utilizados para a inclusão do Wushu nos Jogos Olimpicos de 2008. Para tanto, foi feita uma análise, a partir da perspectiva dos Estudos Culturais, sobre o vídeo apresentado ao Comitê Olímpico Internacional em 2002 para a introdução do Wushu nos Jogos Olímpicos de Pequim, em 2008. A análise foi feita com base em uma "Teoria da Recepção", presente principalmente nas obras de Stuart Hall, que consideram a "centralidade" das questões culturais, bem como as relações de poder envolvidas na sua construção discursiva. Os resultados foram apresentados levando-se em consideração três aspectos: as representações a respeito da China, as representações a respeito do Wushu e a aproximação do Wushu com o modelo ocidental de considerar as práticas corporais. Desse modo, observou-se que as possiveis tensões entre o "tradicional" e o "moderno" parecem não atingir uma contradição no vídeo da IWUF. Os conceitos europeus sobre o esporte aliados ao "Movimento da Nova Cultura" possivelmente inventaram uma nova tradição para as artes marciais, mas essa tradição operou não apenas na sustentação de certas elites e no conceito de nação, mas também enquanto uma posição afirmativa e de resistência diante do processo de colonização realizado por potências estrangeiras.

Palavras-Chave: Kung Fu; Tradição; Modernidade; Olimpismo; Estudos Culturais.

\section{Introdução}

As artes marciais chinesas, também conhecidas como Kung Fu ou Wushu, provavelmente são uma das práticas culturais mais populares que cruzaram as fronteiras da China. De acordo com a Federação Internacional de Wushu ${ }^{1}$ - presidida desde 2003 pelo também Vice-Presidente do Comitê Olímpico Chinês e do Comitê Olímpico Internacional (COI) Yu Zaiqingexistem federaçôes nacionais de Wushu na maioria dos países em todos os continentes, configurando 146 federaçóes membros. Considerando que uma federação é constituída por uma necessidade de institucionalizar uma atividade realizada por um número razoável de praticantes, este montante é considerável. Além disso, a IWUF é a entidade responsável pelas tentativas de inserção do Wushu como esporte olímpico.

Diante do estado atual de certa popularidade dessas práticas corporais, não se pode deixar de considerar que elas sofreram um processo de "esportivizaçáo" que, inicialmente, ocorreu no contexto da transição política do Império para a República Nacional e afetou toda a cultura corporal chinesa ${ }^{2}$. Se este processo também aconteceu em meados do século XIX na sociedade burguesia inglesa, quando o esporte moderno foi fundado 
no contexto das escolas públicas ${ }^{3}$, o mesmo ocorreu na China, mas percorrendo caminhos distintos.

A "esportivização", de acordo com Elias e DuNNING ${ }^{4}$, se refere a uma sensibilização em relação à violência e à agressividade dos jogos com bola da Idade Média, culminando no football e no rugby de meados do século XIX na Inglaterra. O mesmo ocorreu com o boxe que deixa de permitir chutes. Essa sensibilização induziu à criação de códigos e sistemas de regras para essas práticas, permitindo que elas pudessem ser exportadas para outros países, abafando, inclusive, atividades autóctones semelhantes às práticas do modelo esportivo inglês. Atento a isso, esse artigo dará enfoque às transformações ocorridas no âmbito das artes marciais chinesas no contexto da transição política do Império à República Nacional (já no início do século XX), com um efeito geral sobre toda cultura corporal chinesa ${ }^{2}$ e que está relacionado a uma série de rupturas e permanências em relação às tradições do pensamento chinês e a importação de concepçôes estrangeiras 5 .

A cultura corporal europeia chegou à China em um momento de mudanças políticas radicais no país. Essas mudanças, em um curto período, culminaram na queda de um regime imperial e feudal milenares para o estabelecimento do modelo republicano nacionalista de governo em 1911 e da República Popular em 1949. Nesse período, conhecido como Dinastia Qing (清 Qīng) tardia, a China enfrentava as consequências de uma série de conflitos internos e externos, como as duas Guerras do Ópio (鴉片戰爭 Yäpiàn Zhànzhèng), a Guerra Civil ou Rebelião Taiping (太平 Tàiping) e a Rebelião dos Boxers (義和團運動 Yìhétuán Yûndòng), todas do século XIX, relacionados com a colonização ocidental e com o descrédito em relação ao governo estrangeiro Manchu. É notável o resultado desse movimento político, denominado por FAIRBANK e GoldMAN $(2008)^{6}$ de "desmoralização" não apenas econômica, mas também política e intelectual do Império Chinês diante das naçóes ocidentais por meio de acordos e reformas postas em prática pelo governo Qing (清 Qing).

Morris $^{2}$ e Brownell ${ }^{7}$ nos apresentam os caminhos utilizados pelas elites chinesas para superar essa situação desfavorável na tentativa de posicionar a China em pé de igualdade com as potencias imperialistas que recentemente haviam sido seus colonizadores. Essas medidas estavam amplamente ligadas a um repensar sobre o conceito de cultura corporal e a adoção de um novo termo para se referir a esse conceito: Tiyu (體育 $\mathrm{T} \check{1}$ yù), que pode ser aproximadamente traduzido como "cultura física" ou "educação física”. Tal conceito difere das concepçôes sobre o corpo adotadas no período imperial, as quais se baseavam em uma relação íntima entre o ser humano e o poder cósmico, representada na sentença "humanos e natureza como um só" (天人合一 Tiān rén hé yì). O corpo e seus três componentes Jing (精 Jing) ou “essência seminal”, Qi (氣 Qi) ou “energia vital" e Shen (神 Shén) ou "espírito", nessa compreensão, acompanham os movimentos Yin Yang (陰陽 Yìn Yáng) do cosmos. O dualismo entre mente e corpo nunca foi, portanto, claramente articulado como ocorreu nos sistemas de pensamento ocidentais, sendo a experiência subjetiva o paradigma da compreensão sobre o corpo no pensamento chinês ${ }^{7}$. Isso se refletiu na palavra utilizada para denominar o corpo em relação à sua subjetividade: Shen (身 Shèn). Contudo, com o aporte de conceitos e concepçóes provenientes da ciência e educação física do continente europeu, preferiu-se adotar outra nomenclatura que estava relacionada com um "sistema fechado", ou seja, com aspectos físicos e inanimados do corpo: $T i$ (體 $T \breve{1})^{7}$. E é este o ideograma que compóe o novo conceito de cultura corporal no período republicano ${ }^{\mathrm{a}}$.

Assim, ao considerar os modelos chineses de atividade corporal como "antigas" ou "atrasadas", alguns estudiosos escolheram os esportes competitivos como o paradigma para construção da "força do corpo-nação"2. Chama atenção o papel das artes marciais chinesas nesse contexto: o Wushu estava extremamente conectado com essas formas "antigas" de cultura corporal, mas, por outro lado, tanto a República Nacional quanto a Popular elevaram-no à categoria de "cultura física nacional" 2 não sem esforços em "modernizá-lo" e dar-lhe uma conotação científica.

Essa oscilação entre uma tentativa de encontrar uma forma verdadeiramente chinesa de cultura corporal e ter que lidar com uma ideia do atraso das práticas precedentes parecia ser uma preocupação constante que atravessou ambas as Repúblicas que governaram a China Continental ${ }^{2}$. Cheng $^{5}$ expóe que esse paradoxo é uma marca dessa fase da história chinesa. A autora, que busca fornecer um panorama sobre o pensamento chinês, propositalmente não vai além do "Movimento da Nova Cultura" e, especificamente, do "Movimento Quatro de Maio” (五四運動Wǔ si Yùndòng), um ponto crítico da história contemporânea chinesa no qual protestos estudantis e greves gerais contra intervençóes japonesas em 1919 impulsionaram a introdução de novas ideias 
sobre ciência, democracia e patriotismo antiimperialista. $\mathrm{CHENG}^{5}$ afirma que:

No limiar do século XX, a China é dividida entre o peso esmagador da herança do passado e a exigência imperativa para responder ao novo desafio do Ocidente, entendido como o desafio da modernidade. [...] O Movimento Quatro de Maio [...] inaugura uma nova era composta de contradiçốes e conflitos que ainda náo estão resolvidos (p. 28-29, grifos nossos).

\section{Método}

Com o intuito de dialogar com os objetivos propostos, foi realizada uma análise sobre o vídeo ${ }^{8}$ de 9 minutos e 56 segundos produzido pela Federaçáo Internacional de Wushu (IWUF) em 2002 para pleitear o ingresso da modalidade nos Jogos Olímpicos de $2008^{\mathrm{b}}$. Mais do que a dificuldade de acesso aos documentos oficiais, a opção por essa fonte primária se deu pela consideração, baseada no referencial teórico dos Estudos Culturais, de que esse é um produto ou "texto cultural", o qual, do ponto de vista discursivo, tem a mesma relevância de documentos escritos. Isso pois, segundo SiLva' ${ }^{9}$ um texto é qualquer artefato que apresente elementos dotados de signos e significados.

Considerando também que os Estudos Culturais, principalmente o teórico StUART HALL ${ }^{10}$, apontam para a centralidade da cultura na análise das questôes sociais, ou seja, que as questóes simbólicas e discursivas são, atualmente, cruciais para a compreensão dos embates políticos em torno da construção de identidades, é relevante a análise sobre um produto cultural expressamente carregado de sentidos e significados acerca de uma cultura e de suas práticas. Três aspectos foram aqui considerados para análise do vídeo enquanto produção textual que cristaliza os pontos de vista de seus organizadores: as representaçóes a respeito da China, as representaçóes a respeito do Wushu e a aproximação do Wushu com o modelo ocidental de considerar as práticas corporais.

Como referencial teórico de análise, será levada em consideraçáo uma "Teoria da Recepção", presente também nos trabalhos de HaLL ${ }^{11}$. Esse autor defende um modelo para o estudo da comunicaçáo distinto do até entâo consagrado "emissor/mensagem/ receptor", preferindo um sistema o qual toma a mensagem emitida enquanto produto discursivo fruto de um processo que visa "produzir mensagens
Atualmente os choques culturais e políticos enfrentados pela China quando do contato intenso com as experiências de colonização ainda estão presentes na aproximação entre as práticas culturais chinesas e europeias, repercutindo a intensa transformação social ocorrida na China desde o final do século XIX. Assim, o objetivo do artigo é analisar a relação dinâmica entre tradição e modernidade em alguns dos argumentos utilizados para a inclusão do Wushu nos Jogos Olímpicos de 2008.

codificadas na forma de um discurso significativo" (p. 368 $)^{11}$ e que, por outro lado, carece de um processo de decodificação por parte daqueles que são alcançados por esse produto. Para $\mathrm{HALL}^{11}$, há uma simetria entre codificação e decodificação que pode ser mais ou menos apurada a depender da relaçáo que o receptor estabelece com a mensagem difundida. Desse modo, o que está em jogo na discussão sobre a difusão do esporte na cultura chinesa não está relacionado somente à possível dominação europeia, mas também a como esse arcabouço cultural foi recebido pelos chineses.

Além disso, os estudos de Новsваwм ${ }^{12}$ e Thompson ${ }^{13}$ serão também considerados na análise sobre o conceito de tradição. НовSвAwм ${ }^{12}$ define tradição como "um conjunto de práticas, normalmente reguladas por regras tácitas ou abertamente aceitas; tais práticas, de natureza ritual ou simbólica, visam inculcar certos valores e normas de comportamento através da repetição, o que implica, automaticamente, uma continuidade em relação ao passado" (p. 9) ${ }^{12}$. Essa continuidade mantém, sempre que possível, uma conexão com um passado histórico que é amplamente artificial e, em razão disso, são consideradas "tradiçôes inventadas" pelo autor. Diferentemente destas, ligadas às construçóes discursivas da aristocracia inglesa do século XIX, o conceito de "costume", abordado por THOMPSON ${ }^{13}$, está relacionado às classes sociais mais empobrecidas, engendrando um movimento de resistência contra imposições verticais. Nas palavras do autor "A cultura conservadora da plebe quase sempre resiste, em nome do costume, às racionalizaçóes e inovaçóes da economia (...) que os governantes, os comerciantes ou os empregadores querem impor" e conclui 
afirmando que "a cultura popular é rebelde, mas o é em defesa dos costumes. Esses pertencem ao povo, e alguns deles se baseiam realmente em reivindicaçóes muito recentes" (p. 19) ${ }^{13}$.

\section{Resultados e discussão}

O início oficial da empreitada pela inclusão do Wushu nos Jogos Olímpicos deu-se em 2001 quando a Federação Internacional de Wushu foi reconhecida definitivamente pelo COI, após reconhecimento provisório na década de $90^{14}$, e iniciou sua campanha para a inclusão dessa prática no Programa Olímpico ${ }^{15}$. Contudo, não se pode deixar de mencionar que a aprovaçáo, em 2001 da candidatura de Pequim para sediar os Jogos Olímpicos de 2008 foi vista como um momento propício para a inclusão do Wushu nessa edição.

Uma vez negada a inclusão da modalidade como esporte oficial pela Comissão de Programa Olímpico ${ }^{16}$ - muito embora tenha havido uma autorização excepcional por parte do COI para a realização de uma competição de Wushu paralelamente aos Jogos de Beijing ${ }^{17,18}$ - o Comitê Olímpico Internacional reconsiderou o pleito para os Jogos Olímpicos de $2020^{19}$. Contudo, a modalidade não figurou entre as finalistas (Squash, Beisebol/ Softball e a vencedora Luta Olímpica) na decisão anunciada na $125^{\text {a }}$ Sessão do COI, realizada em Buenos Aires em setembro de 2013. Em 2015, o Wushu ganhou uma segunda chance para ser incluído nos Jogos de 2020, juntamente com outros sete esportes, em razão da possibilidade de o Comitê Organizador dos Jogos, que no referido ano serão sediados em Tóquio, selecionar um ou mais esportes para figurar como eventos adicionais no programa olímpico. A decisão sobre essa nova lista será realizada na $129^{a}$ Sessão do COI, no Rio de Janeiro em Agosto de 2016 20, 21 . Além disso, os esforços atuais da IWUF também se concentram na preparação da candidatura como esporte oficial dos Jogos de $2024^{22}$.

Vale ressaltar que, para um esporte fazer parte do rol de modalidades olímpicas, o COI estipula uma série de critérios para a sua inclusão. São três as principais condiçôes para um esporte se tornar olímpico: ser praticado por homens em 75 países de quatro continentes e por mulheres em 40 países em três continentes; o Código da Agência Mundial Antidoping (WADA) deve ser aplicado; não pode depender de propulsão mecânica ${ }^{23}$. No entanto, não basta o cumprimento desses requisitos: a Comissão de Programa Olímpico (Olympic Programme Commission) estipula mais 39 critérios divididos em oitos temas (Geral, Administração, Historia e Tradição, Universalidade, Popularidade, Atletas, Desenvolvimento da Federaçáo Internacional/ Esporte e Finanças) que devem ser analisados com o intuito de selecionar os esportes que melhor se enquadram nas avaliaçóes do COI. Dentre esses critérios estáo a equidade de gênero na gestão das Federaçóes Internacionais, o controle antidoping, a preocupação com a saúde, carreira, diretos e representação dos atletas perante os órgãos gestores, além da cobertura midiática sobre o esporte, a quantidade de patrocinadores envolvidos, os custos arcados com a execução das competiçóes nos Jogos Olímpicos, a lucratividade promovida pela modalidade e o número de eventos competitivos já promovidos pela Federação Internacional ${ }^{24}$.

Há, pois, ao menos dois pontos a se considerar a partir desse cenário. O primeiro é a referência do Wushu enquanto esporte, ou seja, toma-se uma prática corporal marcadamente arraigada na cultura chinesa e que traz consigo uma série de concepçóes historicamente constituídas com base nos sistemas de interpretação de mundo chineses e busca-se uma aproximaçáo dessa prática com um conceito que é, por sua vez, uma construção proveniente da Europa cuja ideia da competição é preponderante. Em segundo lugar, as tentativas de inclusão do Wushu no maior evento do esporte competitivo de alto rendimento da contemporaneidade e ao contexto político envolvido nessa inclusão.

O vídeo foi feito, como dito anteriormente, pela Federação Internacional de Wushu para pleitear, em 2002, a inclusão do esporte nos Jogos Olímpicos de Beijing em 2008. Seus organizadores vislumbraram o evento como um momento oportuno para o Wushu, uma vez que se compreendia que aqueles Jogos poderiam promover uma conexáo entre o "Ocidente" e o "Oriente". Devido ao "milagre econômico" iniciado na década de 1990, a cultura chinesa e toda a sua força, nas palavras do narrador do vídeo, "nunca esteve táo próxima do mundo". De fato, quando se refere a esse "despertar", o vídeo 
mostra diversas imagens de paisagens urbanas marcadas por uma arquitetura portentosa, pelo tráfego intenso de automóveis e por uma grande quantidade de pessoas nas ruas (FIGURAS 1 e 2).

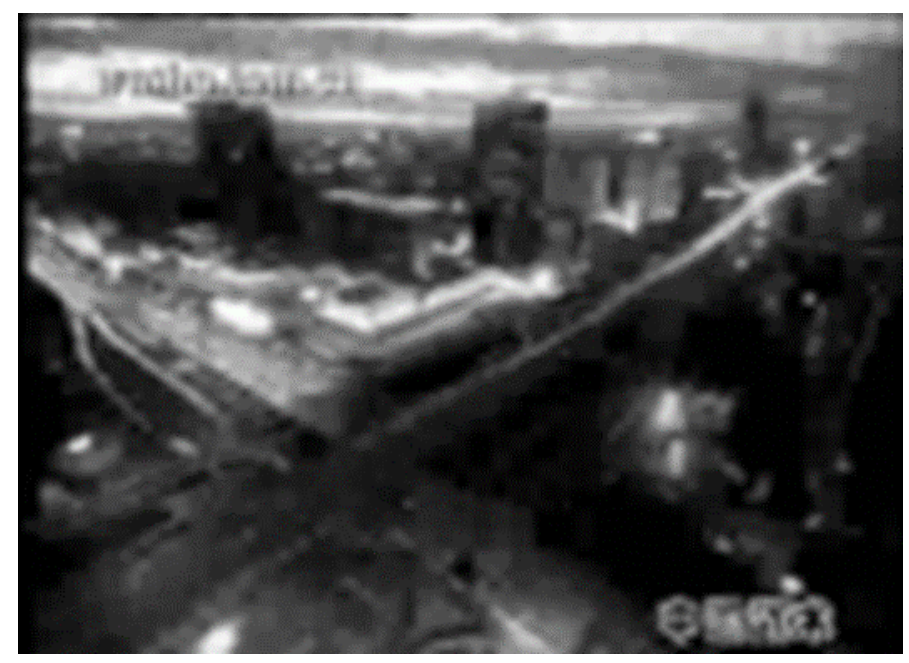

FIGURA 1 - Luzes de uma metrópole chinesa (aos 9 minutos e 6 segundos).

Fonte: IWUF, 2008.

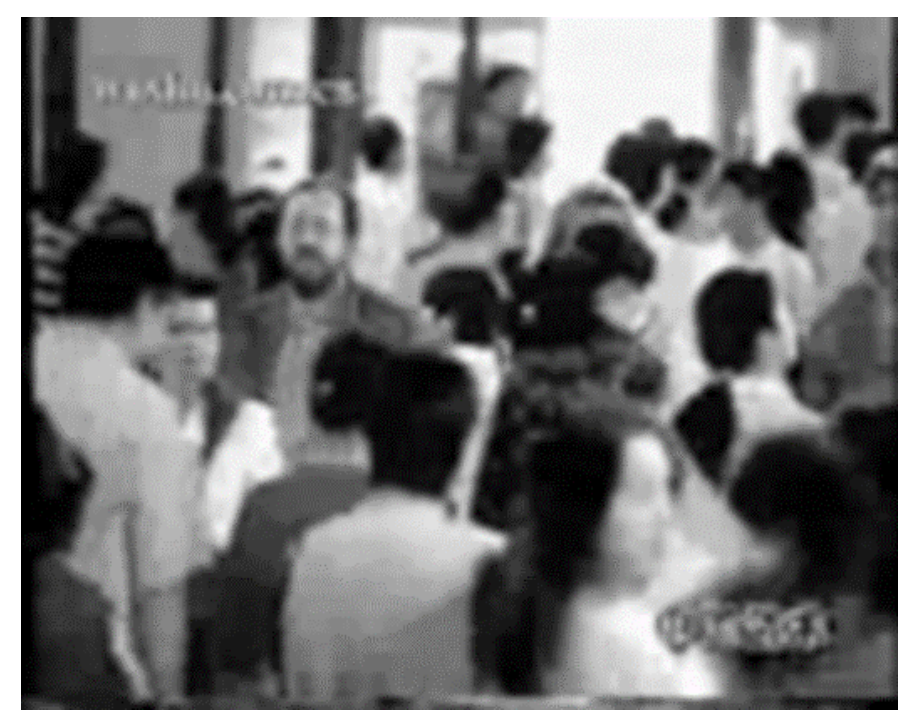

FIGURA 2 - Circulação de pessoas em cidade chinesa (aos 9 minutos e 11 segundos).

Fonte: IWUF, 2008.

Anne-Marie Broudehoux ${ }^{25}$, utilizando a "teoria do espetáculo" para investigar a proliferação de megaprojetos arquitetônicos na Pequim olímpica, afirma que uma função importante do espetáculo é espraiar a visibilidade do Estado na paisagem, pois depende de elementos materiais para que sua qualidade de entidade intangível se faça notar. Ser palco de megaeventos, com os Jogos Olímpicos, náo somente aumenta a visibilidade global como também permite ao governo alterar prioridades urbanas com mais flexibilidade do que normalmente ${ }^{25}$. A autora afirma que após Pequim ter sido selecionada para ser a sede olímpica dos Jogos de 2008, a cidade "passou por uma radical revolução urbana que procurou remodelar sua imagem como metrópole moderna, utilizando para tanto a arquitetura espetacular" (p. 44) Esse projeto de reurbanização sem precedentes foi responsável pela uniformização da paisagem urbana 
sob uma estética marcadamente estrangeira, uma vez que grande parte dos arquitetos contratados não era chinesa, e também por grandes desalojamentos de pessoas e alterações ambientais.

No entanto, a emergência do megaevento precedido pela produção de grandes projetos urbanísticos e arquitetônicos também atraiu os olhares daqueles que o recebem: mesmo não conseguindo o impedimento das construçóes, a pressão exercida por diversos setores da sociedade chinesa motivou uma maior transparência por parte do governo e uma revisão considerável nos gastos e projetos. Nesse sentido, BROUdEHOUX ${ }^{25}$ sinaliza para um "lado produtivo" do espetáculo produzido pelos eventos de escala global já que, ainda que eclipsem diversas contradiçóes, podem promover uma reorganização da consciência política da população incentivada pela "reversão do olhar" à gestão pública dos projetos (FIGURA 3).

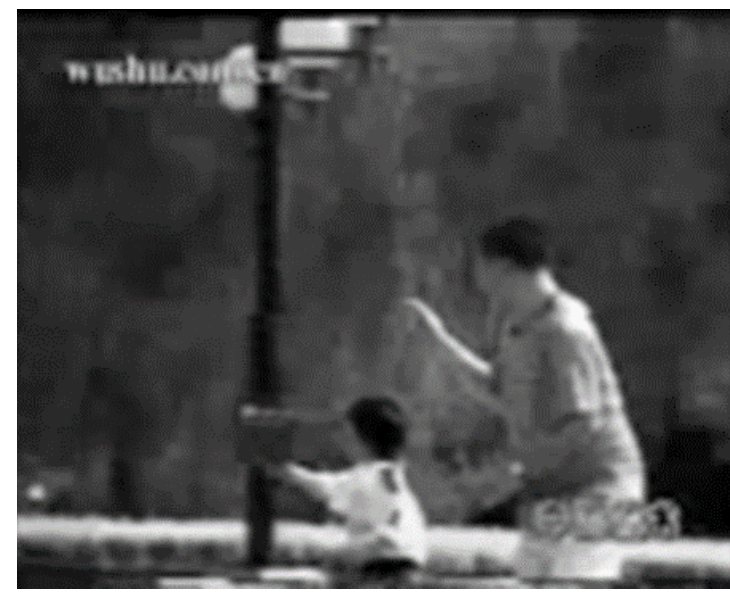

FIGURA 3 -Ocupação de áreas verdes (aos 9 minutos e 16 segundos).

Fonte: IWUF, 2008.

De volta ao vídeo, há também uma tentativa de se mostrar um ambiente, ainda que urbano, com mais áreas verdes e com uma interação geracional entre crianças, adultos e idosos nessa natureza, especialmente praticando esportes. Tais representaçóes podem estar vinculadas a uma tentativa por parte da IWUF de mostrar que - em sendo o país capaz de sediar um evento da magnitude dos Jogos Olímpicos e, mais do que isso, um evento que traz para o território chinês, sobretudo, práticas corporais consideradas "ocidentais" - é a hora e a vez da China fazer o caminho oposto e dar a "sua" contribuiçáo ao universo esportivo. Essa contribuição vem, principalmente, sob a forma esportivizada da arte marcial conhecida como Wushu. Sua primeira menção é acompanhada por uma imagem da fachada do Templo Shaolin, ao qual é creditada a criação mitológica das artes marciais pelo monge budista indiano Bodhidharma (FIGURA 4).

O Wushu é creditado como uma prática originada nos princípios da civilização humana e extremamente ligada com a identidade cultural chinesa. Essa representaçáo é uma construção relativamente recente, pois, como visto, está relacionada com as tentativas de afirmação da identidade nacional chinesa quando do surgimento do período republicano. Além disso, mesmo levando em conta a curta duração do vídeo, náo considera as possíveis mudanças no papel das artes marciais no contexto da história chinesa ou mesmo a multiplicidade de origens e os caminhos divergentes tomados pelos seus diversos estilos, escolas e famílias.

Assim, deu-se preferência pela adoção de uma narrativa de continuidade com um passado antigo que continua progressivamente até os dias atuais, culminando com o que se visualiza como sendo o papel das artes marciais: uma prática que promove aptidão física e competiçóes empolgantes além de ter uma função importante no ensinamento de valores como integridade e moralidade.

Entretanto, entre esses fatores, as questóes sobre a competição são as mais enfatizadas, aludindo para o pioneirismo do time de demonstraçáo nos Jogos de Berlim em 1936 e para a criação da IWUF em 1990, a qual, desde entáo, organiza campeonatos mundiais bienais em vários lugares do mundo. Vale ressaltar que uma das propostas do vídeo é mostrar que tais eventos estáo continuamente tornando o esporte em uma prática "madura, lógica e padronizada". Se por uma lado essa é uma estratégia para alcançar 
os requisitos do COI, por outro estabelece uma relação próxima com os propósitos dos governos nacionalistas e comunistas, quando da criação de seus departamentos de esporte cujos objetivos giravam em torno da unificação de vários ramos das artes marciais chinesas. Isso é bem representado pela escolha das formas padronizadas, ou Taolu (套路 Tàolù), para o "Wushu Competitivo" a ser realizado nos Jogos, não incluindo as formas de combate, ou Sanshou (散手 Sànsh ǒ u). É digno de nota que o website da IWUF também considera um "Wushu Tradicional”, o qual, segundo a Federação, está sob a alçada do "Esporte para Todos" ("Sport for All”) e que é fortemente vinculada à questão da origem étnica tanto de seus difusores quanto do seu arcabouço teórico e técnico (FIGURAS 5, 6 e 7).

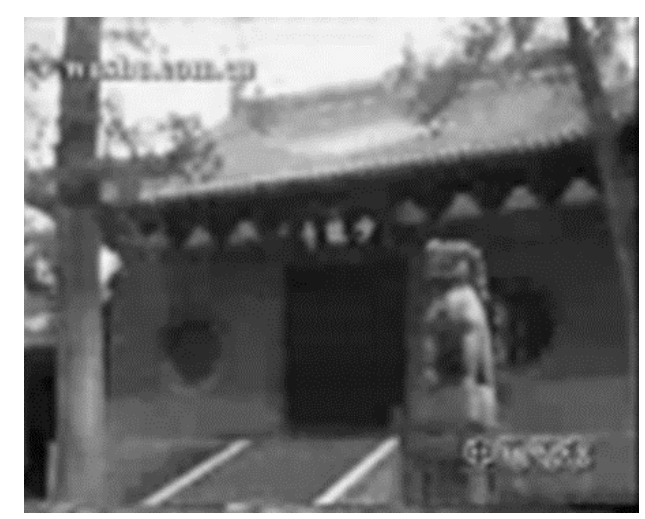

FIGURA 4 - Templo Shaolin (a 1 minuto e 7 segundos).

Fonte: IWUF, 2008.

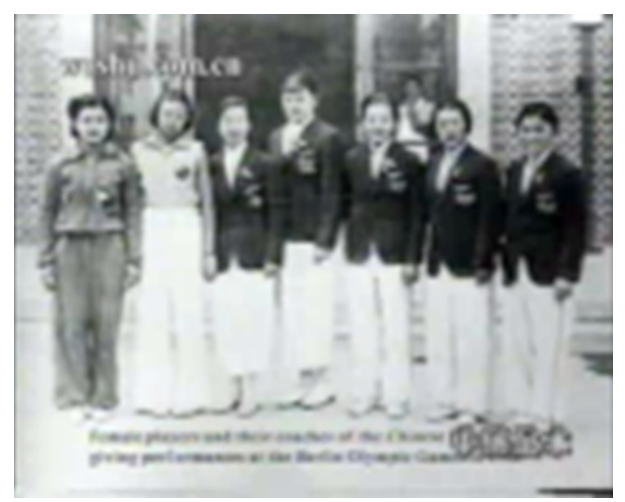

FIGURA 5 - Equipe feminina de Wushu nos Jogos de 1936 (aos 2 minutos e 24 segundos).

Fonte: IWUF, 2008.

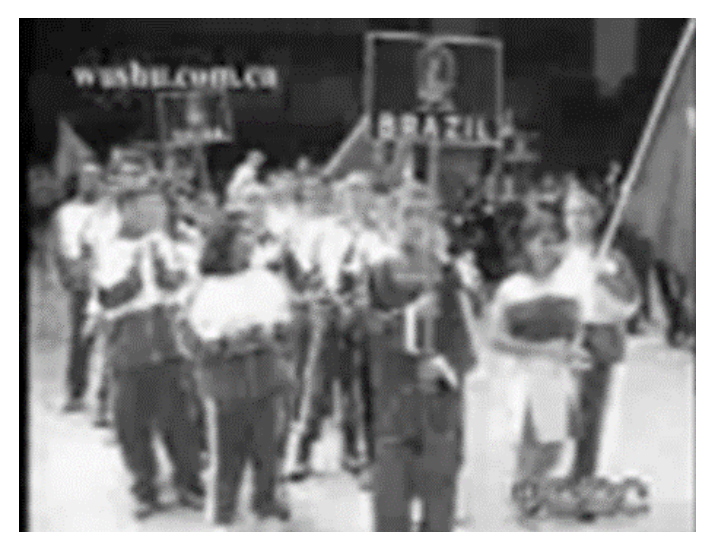

FIGURA 6 - Campeonato Mundial de Wushu - 1991 (aos 3 minutos).

Fonte: IWUF, 2008. 


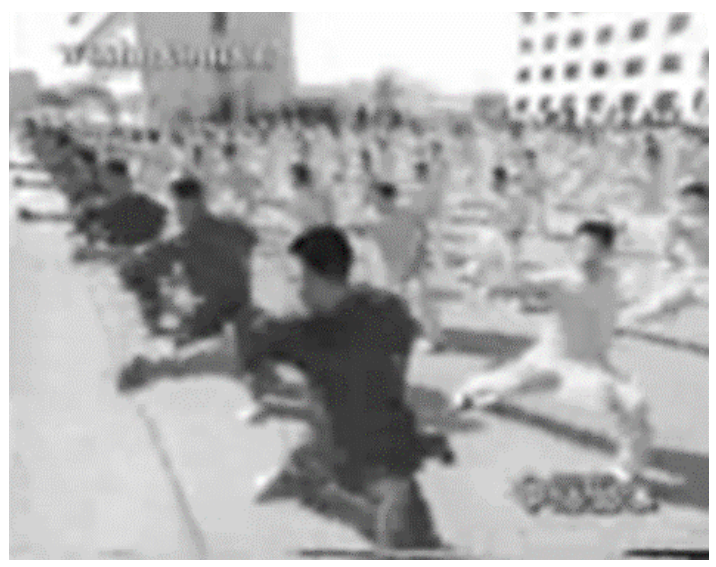

FIGURA 7 - Apresentação coletiva de Wushu (aos 2 minutos e 4 segundos).

Fonte: IWUF, 2008.

Tal dinâmica se assemelha ao que ocorreu com a capoeira baiana a partir da década de 70 e 80 , quando alcança grande vulto na cidade de São Pauloc . Em 1972, a capoeira é reconhecida como esporte e, com a criação da Federação Paulista de Capoeira em 1974, ampliam-se as suas possibilidades de se tornar uma modalidade competitiva. Tal transformação está vinculada, segundo REIs ${ }^{26}$, à esportivização "branca e erudita" proposta nos anos de 1920 pela elite carioca. Em contraposição, dois grupos de capoeiristas, em princípio o "Capitães de d'Areia" e depois o "Cativeiro", passam a contestar essa maneira de enxergar a prática de um modo cada vez mais próximo do que se identifica com o esporte moderno e de descendência europeia. Modo este observado na "unificação da nomenclatura dos golpes e contra-golpes, na regulamentaçáo das normas dos campeonatos, na criação de uma pedagogia e de um sistema de graduação válidos em todo o país e, finalmente, na organização das federaçôes em cada estado e a fundação de uma confederação nacional" (p. 157) ${ }^{26}$.

Ambos os grupos, ainda que de maneira distintas, criticavam a dessacralização e a desafricanização que a Federação impunha à capoeira, afastando-as de seu contexto de luta contra a escravidão e a opressão sofrida pelos negros. Contudo, conforme demonstrou ReIs ${ }^{26}$, esses grupos dissidentes não deixam de adotar certos sinais diacríticos que curiosamente se coadunam com os criados pela Federaçáo, como os sistemas de graduação. Assim, mesmo que em escala distintas, há um processo que parece se assemelhar e fazer cruzar os caminhos tomados pela capoeira e pelo Wushu no sentido de coexistirem diferenças significativas, ou até mesmo conflitantes, entre as suas formas competitivas - mais aproximadas com um referencial "branco" ou europeu sobre o esporte - e suas formas "tradicionais" - mais vinculadas a questôes que extrapolam a competição, como a historicidade, etnicidade e sacralidade da prática (FIGURAS 8 e 9).

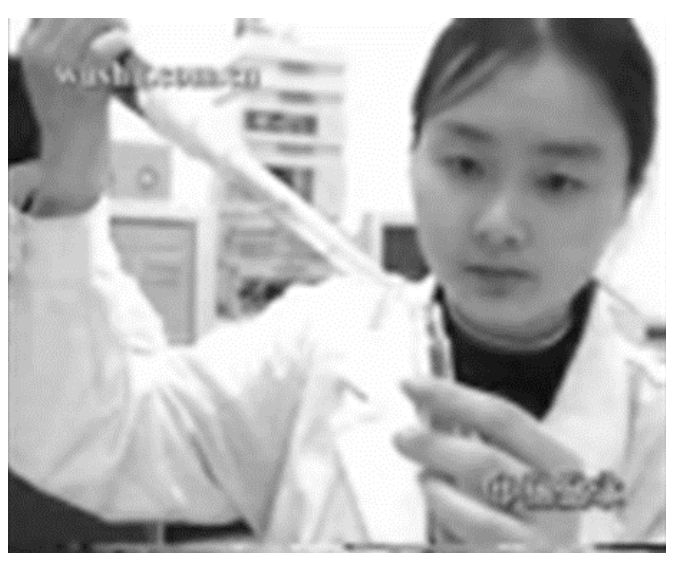

FIGURA 8 - Realização de teste antidoping (aos 8 minutos e 12 segundos)

Fonte: IWUF, 2008. 


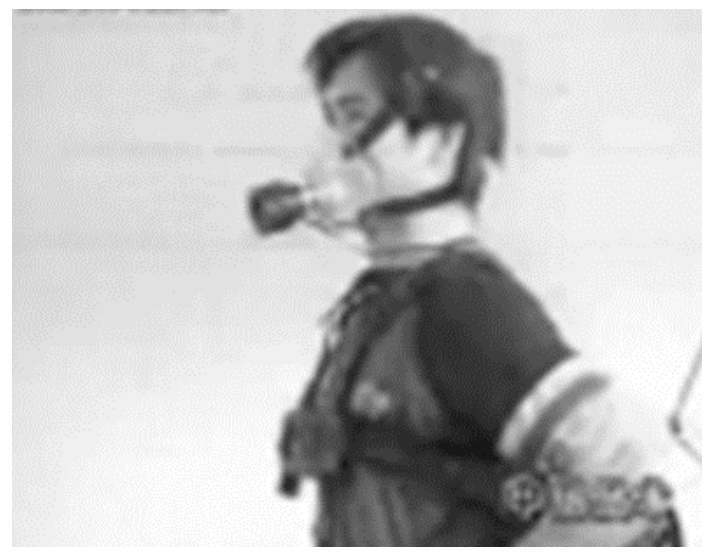

FIGURA 9 - Performance com ergoespirômetro portátil (aos 7 minutos e 55 segundos).

Fonte: IWUF, 2008.

Já no vídeo, outra demonstração do processo de esportivização vivenciado pelo Wushu reside no tempo dedicado pelos organizadores do vídeo para tecer comentários sobre o rigoroso sistema antidoping que é desempenhado nos campeonatos mundiais e sobre o alto nível de competitividade dos atletas envolvidos nesses eventos. O discurso é acompanhado por imagens de laboratórios analisando amostras e um atleta realizando uma forma padronizada de Wushu com um equipamento similar a um ergoespirômetro portátil. Se, novamente, esse fato é usado para se compatibilizar com os regulamentos postulados pelo COI, essa relação estabelece outra similaridade com as preocupaçóes do início do século XX: para além da padronização, há uma preocupação de demonstrar um trato científico para com as artes marciais.

Seria possível cogitar, portanto, que o Wushu foi "dominado" pela cultura esportiva em uma relação completamente verticalizada. Contudo, essa não parece ser a visão dos organizadores do vídeo. Essa forma de olhar para o Wushu mostra, ao revés, uma tentativa de reconfiguração de um forte elemento da cultura chinesa, as artes marciais, em contraste com outro europeu não menos intenso, o esporte. Desse modo, ainda que não se neguem as mudanças ocasionadas nas artes marciais chinesas originadas pelo contato mais intenso com a "cultura europeia" no início do século XX, não é possível afirmar que essa mudança resultou em uma transformação radical e uma plena adoção desses valores. Essa noção é explicitada no vídeo quando a narração diz:
Hoje o povo chinês não está apenas abraçando o nobre espírito dos Jogos Olímpicos, mas também se esforçando para integrar seus característicos esportes orientais com aqueles do mundo. Ao longo do século passado, o Wushu foi levado para todas as partes do mundo .

A partir do cotejamento da análise do vídeo, realizado no início do século XXI, com o momento histórico do início do processo de esportivização do Wushu, é possível afirmar que as artes marciais na China fizeram parte de um duplo movimento de resistência ao poder autoritário principalmente dos colonizadores (japoneses e europeus), de uma forma que se assemelha ao "costume" descrito por Thompson ${ }^{13}$, e ao mesmo tempo, foram adotadas pelos administradores republicanos (nacionalistas e comunistas) como um forte elemento cultural agregador para a "Nação chinesa", se aproximando do conceito de "tradição inventada" de Новвваwм ${ }^{12}$ ou ainda, ao de "comunidades imaginadas" proposto por ANDERSON ${ }^{27}$.

Assim, as possíveis tensões entre o "tradicional" e o "moderno" parecem não atingir uma contradição no vídeo da IWUF. Em vez disso, a confluência de elementos "ocidentais" e "orientais", ainda que se possa questionar essa divisão, é desejada. Os Jogos Olímpicos de Pequim em 2008, uma primeira tentativa dessa aproximação no cenário esportivo em escala global, impulsionou as iniciativas para a inclusão do Wushu nesse mega evento. Esse movimento sinaliza uma busca por harmonia entre os valores chineses, representados pelas suas artes marciais, e os europeus, simbolizados pelo 
esporte. Isso pode ser visto, então, como o auge do processo de reestruturação da cultura corporal chinesa, iniciado há aproximadamente um século, ou seja, a reconfiguração das identidades nacionais e culturais chinesas com a recepção de elementos externos.

A dinâmica entre as "tradições inventadas" e os "costumes" ajuda a compreender como as artes marciais chinesas e seus agentes lidaram com as rápidas mudanças ocorridas na virada do século $\mathrm{XX}$, entre as quais também está incluída a migração de diversos mestres para fora da China. Os conceitos europeus sobre o esporte aliados ao "Movimento da Nova Cultura" possivelmente inventaram uma nova tradição para as artes marciais, mas essa tradição operou náo apenas na sustentação de certas elites e no conceito de nação, mas também enquanto uma posição afirmativa e de resistência diante do processo de colonização realizado por potências estrangeiras.

\section{Notas}

a. Susan Brownell (2008, p. 52) faz uma comparação entre os conceitos chineses de Shen (身 Shēn) e Ti (體 T r i ) e as palavras Leib (“corpo-sujeito") e Körper (“corpo-objeto”) da língua alemã para realizar essa discussão.

b. $\mathrm{O}$ arquivo do vídeo não se encontra mais disponível no link originalmente referenciado e nem em qualquer outro local no website da IWUF, o qual passou por uma reformulação que culminou com a exclusão de diversos conteúdos. Contudo, é possível acessá-lo no site de compartilhamento de vídeos YouTube a partir desse link: https://youtu. be/9wgfUWLBbak

c. Vale notar que é nessa mesma época que a arte marcial difundida com o nome de Kung-Fu, dentre outras de origem asiática, é vastamente difundida no meio cinematográfico e televisivo.

d. Traduçáo livre. No original: "Today the Chinese people are not only embracing the noble spirit of the Olympics, but also exerting themselves to integrate their distinctive oriental sports with those of the world. Over the past century, Wushu has brought to all part of the world".

e. Benedict Anderson (2008) define a ideia de nação como “comunidades imaginadas" no sentido de que as nações são formadas não apenas por determinações geográficas, linguísticas ou consanguíneas, mas, principalmente, por um senso, uma "imaginaçáo", de que seus membros fazem parte de um mesmo grupo coeso partilhando um modo de vida semelhante.

\section{Abstract}

The "challenge of modernity" and the Chinese marcial arts: an analysis on the inclusion of Wushu in the Olympic Games

The "challenge of modernity" and the Chinese martial arts: an analysis on the inclusion of Wushu in the Olympic Games Chinese martial arts (Kung Fu or Wushu) are probably one of the most popular cultural practices that crossed the borders of China. According to the International Wushu Federation (IWUF) there are national associations in most countries of all continents, configuring 146 member associations. Moreover, the IWUF is responsible for the claim of Wushu as an Olympic sport. Thus, the aim of this article is to analyze the dynamic relationship between tradition and modernity in some of the arguments for the inclusion of Wushu at the 2008 Olympic Games. Therefore, an analysis was made from the perspective of the Cultural Studies on the video submitted to the International Olympic Committee in 2002 for the pledge of Wushu at the Beijing Olympic Games in 2008. The analysis was based on a "Theory of Reception", mainly present in the works of Stuart Hall, who consider the "centrality" cultural issues as well as the power relations involved in its discursive construction. The results were presented taking into account three aspects: the representations about China, the representations of Wushu and the approach of Wushu with the Western model to consider body practices. Thereby, it was observed that the possible tensions between "traditional" and "modern" does not seem to reach a contradiction 
in the video IWUF. European concepts of the sport plus the "New Culture Movement" possibly invented a new tradition for the martial arts, but this tradition has operated not only in support of certain elites and the concept of nation, but also as an affirmative position and strength before the colonization process carried out by foreign powers.

KEYWORDS: Kung Fu; Tradition; Modernity; Olympism; Cultural studies.

\section{Referências}

1. International Wushu Federation (IWUF) [Internet]. Beijing: IWUF;2018 [citado 15 Mar. 2016]. Disponível em: http://www.iwuf.org/iwuf/.

2. Morris A. The marrow of the nation: a history of sport and physical culture in republican China. California: University of California Press; 2004.

3. Rubio K. Medalhistas olímpicos brasileiros: histórias, memórias e imaginário. São Paulo: Casa do Psicólogo; 2006.

4. Elias N, Dunning E. A busca da excitação. Lisboa: Difel; 1992.

5. Cheng A. História do pensamento chinês. Petrópolis: Vozes; 2008.

6. Fairbank JK, Goldman M. China: uma nova história. Porto Alegre: L\&PM; 2008.

7. Brownell S. Beijing's Games: What the Olympics Mean to China. Lanham: Rowman \& Littlefield Publishers; 2008.

8. International Wushu Federation (IWUF). Wushu bidding for the Olympic Games [Internet]. Beijing: IWUF; 2008 [citado 10 Ago. 2012]. Disponível em: http://www.iwuf.org/news_news1_1.asp?id=226.

9. Silva TT. A produção social da identidade e da diferença. In: Silva TT, Hall S, Woodward K. Identidade e diferença: a perspectiva dos Estudos Culturais. Petrópolis: Vozes; 2000. p. 73-102.

10. Hall S. A centralidade da cultura: notas sobre as revoluçóes culturais do nosso tempo. Educação \& Realidade. 1997;22(2):15-46.

11. Hall S. Da diáspora: identidades e mediaçôes culturais. Belo Horizonte: Editora UFMG; 2003.

12. Hobsbawm E. Introdução: a invenção das tradições. In: Hobsbawm E, Ranger T. A invenção das tradições. São Paulo: Paz e Terra; 2006. p. 9-23.

13. Thompson EP. Costumes em Comum: estudos sobre a cultura popular tradicional. São Paulo: Companhia das Letras; 1998.

14. Comitê Olímpico Internacional (COI). Final Report on the XXVII Olympiad 1997-2000 [Internet]. Lausanne: COI; 2002 [citado 18 Out. 2012]. Disponível em: http://www.olympic.org/Documents/Reports/EN/en_report_677.pdf.

15. International Wushu Federation (IWUF). IWUF Magazine 2014 [Internet]. Beijing: IWUF; 2015 [citado 15 Mar. 2016]. Disponível em: https://issuu.com/americanwushusociety/docs/wushu_-_iwuf_magazine_2014_.

16. Comitê Olímpico Internacional (COI). Olympic Programme Commission: Review of the Olympic Programme and the recommendations on the Programme of the Games of the XXIX Olympiad, Beijing 2008. 2008 [Internet]. Lausanne: COI; 2002 [citado 16 Ago. 2012]. Disponível em: http://www.olympic.org/Assets/ImportedNews/Documents/en_report_527.pdf.

17. China. Wushu, still a long way from Olympics [Internet]. Beijing: China.org.cn; 2008 [citado Out. 2012]. Disponível em: http://www.china.org.cn/sports/news/2008-08/08/content_16164936.htm.

18. Mocarzel RCS, Murad M, Capinussú JM. O Kung-Fu Wushu e os Jogos Olímpicos: história e possibilidades de inserção. Corpus Et Scientia. 2002;9(1):115-25.

19. Comitê Olímpico Internacional (COI). 17th Athletes Bulletin [Internet]. Lausanne: COI; 2011[citado 16 Ago. 2012]. Disponível em: http://www.olympic.org/Documents/Elite_Athletes/17th-athletes-bulletin-en.pdf.

20. Comitê Olímpico Internacional (COI). Tokyo 2020 Opens Application Process for 2020 Games Additional Events [Internet]. Lausanne: COI; 2015 [citado 15 Mar. 2016]. Disponível em: http://www.olympic.org/news/tokyo-2020-opens-applicationprocess-for-2020-games-additional-events/245178.

21. The Tokyo Organising Committee of the Olympic and Paralympic Games. Tokyo 2020 to Announce its Proposed Additional Events to the IOC on 28 September [Internet]. Tokyo: Tokyo 2020; 2015[citado 15 Mar. 2016]. Disponível em: https:// tokyo2020.jp/en/news/notice/20150918-01.html.

22. International Wushu Federation (IWUF). About the International Wushu Federation (IWUF) [Internet]. Beijing: IWUF; 2015[citado 15 Mar. 2016]. Disponível em: http://www.iwuf.org/upload/2015/1023/6dd5503b6a34ac4092a46077954 7e62f44739726.pdf. 
23. The Olympic Museum Educational and Cultural Services. The Modern Olympic Games. The Olympic Museum [Internet]. 2007[citado em 2013 Mar 6];(3):1-18. Disponível em: http://www.olympic.org/Documents/Reports/EN/en_report_668.pdf.

24. Comitê Olímpico Internacional (COI). Evaluation criteria for sports and disciplines [Internet]. Lausanne: COI; 2012 [citado 6 Mar. 2013]. Disponível em: http://www.olympic.org/Documents/Commissions_PDFfiles/Programme_ commission/2012-06-12-IOC-evaluation-criteria-for-sports-and-disciplines.docx.pdf.

25. Broudehoux AM. Arquiteturas do espetáculo integrado na olimpíada de Pequim. Novos Estudos-Cebrap. 2011 ;(89):39-56.

26. Reis LVS. O mundo de pernas pro ar: a capoeira no Brasil. São Paulo: Publisher Brasil; 2000.

27. Anderson B. Comunidades imaginadas. São Paulo: Companhia das Letras; 2008.

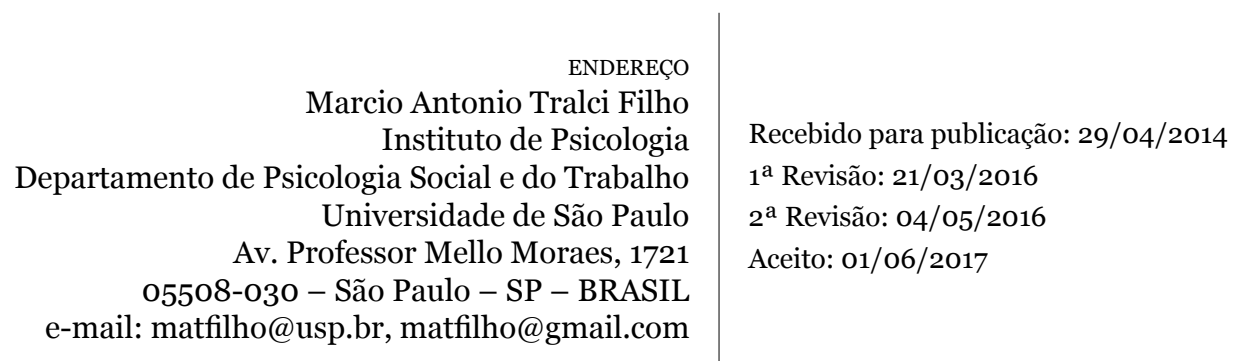

